

Received 20th October 2016 Accepted 8th February 2017

DOI: $10.1039 / c 6 r a 25509 d$

rsc.li/rsc-advances
Cite this: RSC Adv., 2017, 7, 12629

\section{Experimental studies of hydrocarbon separation on zeolites, activated carbons and MOFs for applications in natural gas processing}

\author{
Yunxia Yang, ${ }^{* a}$ Nick Burke, ${ }^{\text {a }}$ Suhaib Ali, ${ }^{\text {a }}$ Stanley Huang, ${ }^{\mathrm{b}}$ Seng Lim ${ }^{\mathrm{a}}$ \\ and Yonggang Zhu ${ }^{\mathrm{C}}$
}

Separation of minor hydrocarbon components in natural gas is necessary prior to liquefaction to avoid operational (plugging of equipment) and product specification issues. While there have been many studies describing adsorption of gases on solid materials there have been relatively few focused on decreasing concentrations of light hydrocarbons in methane in non-equilibrium experimental configurations. In order to best understand the chemistry of competitive adsorption of saturated hydrocarbons for gas processing applications we investigated light hydrocarbon dynamic adsorption properties on 16 solid adsorbents of different structures and chemistries. The best adsorbents, as determined by adsorption capacity, were tested for their ability to separate higher molecular weight hydrocarbons from methane. It is found that for charged frameworks, the induced dipole moment between the adsorbent and adsorbate plays the most important role in adsorption capacity. For uncharged frameworks, pore size plays the critical role in adsorption: micropores are more effective than mesopores. For separation of mixtures of methane, ethane, propane and butane, the kinetics of adsorption must also be considered. Of the materials tested, a carbon derived from coal and activated with steam (carbon \#5 (37771)), zeolite KX and zeolite 5A were the best in terms of adsorption and separation capability. These materials show promise for separating light hydrocarbons of similar chemical nature.

\section{Introduction}

Natural gas is predicted to undergo a drastic increase in demand over coming decades for energy production due to its relative abundance and lower carbon footprint in comparison to other fossil resources. Natural gas can be piped directly to where it is required or can be liquefied through a refrigeration process to make Liquefied Natural Gas (LNG). Raw natural gas produced from the wellhead typically consists of methane and $\mathrm{C}_{2+}$ hydrocarbons such as ethane, propane and other heavier hydrocarbons amongst a range of other compounds. These minor hydrocarbon fractions must be lowered to avoid operational issues such as freezing and plugging in scrub columns during liquefaction and to meet product specifications before pipeline distribution. Typically, refrigeration cycles are used to separate out heavier unsaturated hydrocarbons from methane for LNG production. It is generally considered that solid sorbents are not best applied to large-scale LNG production or gas processing. However, opportunities might exist for

${ }^{a}$ CSIRO Energy, 71 Normanby Rd, Clayton North, Victoria 3168, Australia. E-mail: yunxia.yang@csiro.au

${ }^{b}$ Chevron Energy Technology Company, Houston, TX 77002, USA

${ }^{c}$ Harbin Institute of Technology (ShenZhen), ShenZhen, 518055, China application of solid sorbents in the small-scale processing of natural gas.

Separation by adsorption is one technology that offers high selectivity to the desired product; is reliable; and has a capital cost and energy consumption comparable to similar separation techniques. Adsorption has been applied for air separation, gas dehydration and $\mathrm{CO}_{2}$ separation amongst others. ${ }^{1}$ Some work has reported the study of adsorption of saturated hydrocarbons or the separation of saturated and unsaturated hydrocarbons but fewer reports exist describing the dynamic separation of mixtures containing solely saturated hydrocarbon molecules. $^{2-10}$ Small saturated hydrocarbons have similar physical dimensions (methane, ethane and propane have kinetic diameters of $4.0 \AA$ \& $4.4 \AA$ and $4.9 \AA$ respectively). And unlike unsaturated hydrocarbons, none of the saturated hydrocarbon molecules displays strong electronic interactions with solid surfaces, making study of their sorption behavior more difficult.

Zeolites are microporous crystalline solids that have been investigated in many gas adsorption systems, such as $\mathrm{CO}_{2}$ separation and air separation. ${ }^{\mathbf{4 1 1 - 1 7}}$ Because of their electronically charged framework structures, they are often regarded as candidates for separating mixtures of gases with different charge properties. In our previous work, we studied the effect of charge-compensating cations for propane adsorption on 
zeolite-X. The dynamic experimental results revealed that all Xzeolites examined displayed an affinity for propane adsorption. Interestingly, unlike many non-zeolite adsorbent materials, such as carbons, surface area and pore size alone did not necessarily determine propane adsorption capacity. Of greater importance was the nature of the charge-compensating cation: specifically valence, number of ions ( $\mathrm{Si}: \mathrm{Al}$ ratio) and cation size. ${ }^{18}$

SBA-15, a siliceous material that contains micropores and narrow mesopores was chosen to explore its hydrocarbon adsorption properties. It has been identified as having potential for small gas molecule adsorption..$^{\mathbf{1 9 2 0}}$ For comparison, one very high silica content microporous zeolite, Beta (BEA) zeolite (CP 811C-300, $\mathrm{SiO}_{2} / \mathrm{Al}_{2} \mathrm{O}_{3}=300$ ) was also chosen to compare the microporous and mesoporous materials.

Metal Organic Frameworks (MOFs) are another type of highly porous material developed in recent years. Their high porosity, surface area and tunable structure have made them potential candidates for gas adsorption. ${ }^{\mathbf{1 3 , 2 1 , 2 2}}$ Reports on separating saturated hydrocarbons by MOFs are limited. Because it has high water tolerance and is well characterised ${ }^{23,24}$ copper benzene tricarboxylate $\left(\mathrm{Cu}_{3}(\mathrm{BTC})_{2}\right)$ or $\mathrm{Cu}$-BTC has been chosen as a representative MOF adsorbent to test its hydrocarbon adsorption properties.

In the current work, hydrocarbon adsorption on 16 solid sorbent materials with different surface chemistries were investigated through dynamic breakthrough experiments. The materials chosen were $\mathrm{Y}$ zeolites exchanged with $\mathrm{Na}^{+}, \mathrm{Li}^{+}, \mathrm{K}^{+}$, $\mathrm{Ca}^{2+}, \mathrm{La}^{3+}$; A-zeolites including $\mathrm{KA}$ (3A), NaA (4A), and CaA (5A), 5 type of commercial carbon materials, beta-zeolite, SBA-15 and $\mathrm{Cu}$-BTC. Adsorption and desorption cycles were run on selected adsorbents to examine their durability. Sorption mechanisms and chemistries underlying the observed sorption behavior are proposed.

\section{Experimental}

\subsection{Materials and synthesis}

The A zeolites, Faujasite $\mathrm{NaY}, \mathrm{NaX}$ zeolite, beta-zeolite $\left(\mathrm{SiO}_{2} /\right.$ $\mathrm{Al}_{2} \mathrm{O}_{3}=300$ ) and all the carbon samples were purchased from Sigma Aldrich.

LiY, KY, CaY and LaY, LiX, KX, CaX and LaX were synthesized in our lab. In general, the procedure was to weigh a certain amount of the zeolite $(20 \mathrm{~g})$ in a glass conical flask stirred with a magnetic stirrer bar. The desired amount of salt solution (0.5 M LiCl, $1 \mathrm{M} \mathrm{KCl,} 1 \mathrm{M} \mathrm{CaCl}_{2}, 0.1 \mathrm{M} \mathrm{LaCl}_{3}$ ) was added to the flask. The $\mathrm{pH}$ of the solution was adjusted to $\sim 9$ by $\mathrm{KOH}$ if necessary. The conical flask was placed in an oil bath, stirred and heated at $65-80{ }^{\circ} \mathrm{C}$ overnight. Then, the suspension was filtered and washed with hot distilled water to remove the excess salt. The above ion-exchange procedure was repeated twice to ensure a high degree of ion-exchange. Finally, the sample was filtered and washed with hot distilled water and dried in the oven overnight at $\sim 100{ }^{\circ} \mathrm{C}$.

The metal organic framework material, $\mathrm{Cu}-\mathrm{BTC}$ and the structured mesoporous pure siliceous SBA-15 were synthesized according to literature. ${ }^{25,26}$

\subsection{Characterization}

Nitrogen adsorption isotherms were measured using a Micromeritics Tristar 3000. BET Surface area and pore volume of the synthesized adsorbents were obtained from these isotherms. Samples were degassed on a vacuum prep at $350{ }^{\circ} \mathrm{C}$ overnight before analysis. Cu-BTC degassing temperature was $150{ }^{\circ} \mathrm{C}$. Langmuir/BET surface area was extracted from the adsorption isotherm at a relative pressure $p / p_{0}$ less than 0.12 . Micropore volume was obtained by $t$-plot and total pore volume by single point pore volume at a relative pressure $p / p_{0}=0.99$. Pore size distribution was obtained by using non-local density functional theory for slit pore geometry. Elemental analysis was conducted on a Philips PW2404 XRF instrument. Li element was analysed by Varian Vista ICP-OES. X-ray diffraction (XRD) data were collected on a Philips PW 1140/90 using a $\mathrm{Cu} \mathrm{K} \alpha$ radiation source at $25 \mathrm{kV}$ and $40 \mathrm{~mA}$.

\subsection{Dynamic breakthrough experiments}

The breakthrough apparatus was developed in our previous work to measure the gas breakthrough curves (Fig. 1). ${ }^{18}$ It consisted of three main sections: preparation section; adsorption section; and the analytical section. In the gas preparation section, the purge gas was high purity Ar gas (99.999\%) which was used to purge the system through the inert gas line and the reactor before the hydrocarbon gas was introduced. The adsorption section used a $1.0 \mathrm{~mol} \%$ propane or ethane in helium gas or artificial gas mixture (0.504 mol\% $n$-butane, $2.51 \mathrm{~mol} \%$ propane, $4.98 \mathrm{~mol} \%$ ethane), which passed through the fuel gas line and the reactor. Both lines ran into a four-port crossover valve.

The whole set up was run isothermally $\left(\sim 26^{\circ} \mathrm{C}\right)$. Valve positions, gas flowrate, pressure and temperature were completely automated and controlled by an in-house designed LabView program. The gas from the reactor outlet was analyzed and quantified by a Pfeiffer Mass Spectrometer (MS). The breakthrough curve is a plot of the reactor outlet gas concentration against adsorption time. When the outlet gas concentration reaches the inlet gas concentration, it is called as a complete breakthrough. Generally, the breakthrough curve represents adsorption characteristics between the adsorbate and the adsorbent. The adsorption reactor consisted of a $6 \mathrm{~mm}$ i.d. stainless

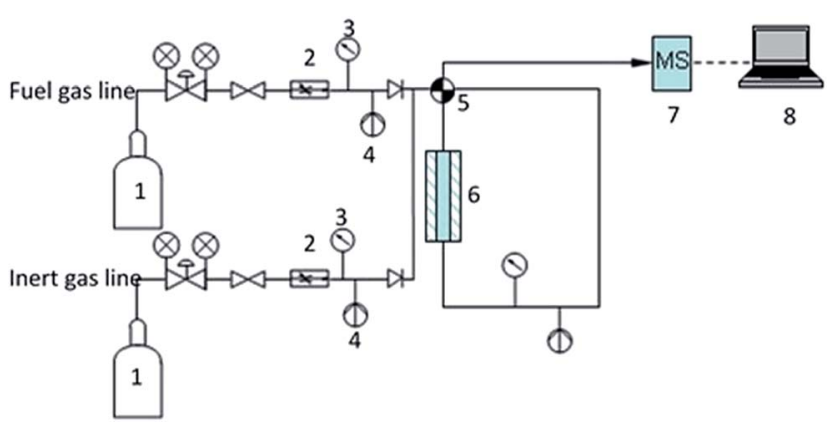

Fig. 1 A schematic diagram of the dynamic breakthrough rig used in our work. (1) Gas bottle. (2) Mass flow controller. (3) Pressure indicator. (4) Temperature indicator. (5) Four port valve. (6) Reactor (adsorption column) and furnace. (7) Mass Spectrometer. (8) Laptop for MS. 
steel column. All adsorbents were pelletized to an average size of 300-500 $\mu \mathrm{m}$ (without using binder) to avoid pressure drop across the bed. During the breakthrough experiment, the reactor column was filled with adsorbents ( $0.4 \mathrm{~g})$ which were pre-degassed on a vacuum prep unit (Micromeritics, USA) at $350{ }^{\circ} \mathrm{C}$ overnight and packed uniformly to about $35 \mathrm{~mm}$ in height. After packing, Ar gas from the inert line purged the system and reactor at ambient temperature until the MS baselines were stable. Then, hydrocarbon gas from fuel gas line was introduced into the reactor at

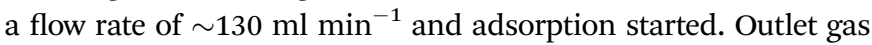
concentrations were monitored online throughout the process by the MS. When the saturation state was reached, fuel gas feed was terminated. At this point Ar was introduced and reactor purging started while heating up the reactor by the furnace to $\sim 60{ }^{\circ} \mathrm{C}$ to desorb any adsorbed material and regenerate the adsorbent.

The propane or ethane adsorption capacity on the adsorbent was obtained by integrating the reactor outlet gas concentration profiles over the entire breakthrough time, $q=\int_{0}^{t} u \times\left(C_{\text {in }}-C_{\text {out }}\right) \mathrm{d} t$, where $q$ was the amount adsorbed; $u$ was the gas flow rate, $\mathrm{ml} \mathrm{min}^{-1}$; $C_{\text {in }}$ was the inlet gas concentration and $C_{\text {out }}$ was the outlet gas concentration. $t$ was the time that it took for the hydrocarbon gas to reach a complete breakthrough from the adsorbent bed after adsorption started.

An artificial natural gas containing $0.504 \mathrm{~mol} \% \mathrm{n}$-butane, $2.51 \mathrm{~mol} \%$ propane, $4.98 \mathrm{~mol} \%$ ethane balanced in methane that simulated the natural gas prior to liquefaction was used to investigate the hydrocarbon mixture separation properties. The size of the gas molecules of interest is given in Table 1. The adsorbents chosen in this experiment were the best (adsorbents with the highest capacities for the sorbate gases tested) identified in each group of adsorbents in the current work, namely zeolites 5A, KX, KY, and carbon \#5.

\section{Results and discussion}

\subsection{Propane adsorption}

3.1.1 Propane adsorption on $\mathrm{Y}$ zeolites. The $\mathrm{Y}$ zeolites tested in our work were a commercial NaY and 4 self-

Table 1 Gas molecule size

\begin{tabular}{lllll}
\hline Gas molecule & Methane & Ethane & Propane & Butane \\
Critical diameter, A & 4.0 & 4.4 & 4.9 & 5.1
\end{tabular}

synthesized Y zeolites, LiY, KY, CaY, and LaY. The elemental analysis for all these $\mathrm{Y}$ zeolites is in Table 2.

It was clear from the elemental analysis results that the ionexchange of the zeolites was not $100 \%$ complete. Only a fraction of $\mathrm{Na}$ ions was replaced by the target ions. Therefore, in the synthesised zeolite framework, ions were a mixture of ionexchanged ions and original $\mathrm{Na}$ ions. The XRD results confirmed the FAU framework structural of all the ionexchanged zeolites, Fig. 2a and no major structure change observed. No information is available on the compensating ions from XRD. However, XRF information (Table 2) gives information on concentration of these cations.

Propane breakthrough curves for all the Y zeolites are shown in Fig. 2b. The slope of the adsorption front determines the extent to which the capacity of an adsorbent bed can be utilised and also reflects the adsorption rate. Therefore, the shape of the curve is very important in determining the useful length of the adsorption bed. In actual practice, the steepness of the concentration profiles can increase or decrease, depending on the type of adsorption involved. In our case, LaY and CaY had the steepest slopes, indicating fast adsorption kinetics and a more complete utilization of the adsorbent bed which is a similar conclusion that was drawn for propane adsorption on the $\mathrm{X}$ zeolites having La and $\mathrm{Ca}$ as charge balancing ions. ${ }^{18}$ This suggests strong binding between the Y zeolites containing La and $\mathrm{Ca}$ and the propane adsorbate. ${ }^{18} \mathrm{Y}$ zeolites exchanged with $\mathrm{Li}$ and $\mathrm{Na}$ had less steep slopes, suggesting slower adsorption kinetics and consequently a lower useful bed length than the La and Ca-exchanged Y zeolites. The breakthrough curve for $\mathrm{KY}$ had a less steep slope compared to the rest of the Y zeolites, suggesting slower adsorption kinetics. $\mathrm{K}^{+}$ions are the largest of any used in this study (see Table 3). The relatively large size of these ions could block access to some of the adsorption sites. In this case, axial dispersion may come into effect and a broader mass transfer zone was occurring. $\mathrm{K}^{+}$ions, especially after solvation with water molecules captured during the packing step may have occupied a window site of the supercage in $\mathrm{Y}$ zeolite, causing a partial blockage of the pores, resulting in slower diffusion of propane through the window into the supercage. Propane breakthrough through the adsorption bed and the adsorption capacity on all the Y zeolites followed the same trend as $\mathrm{KY}>\mathrm{LiY} \geq \mathrm{NaY} \geq \mathrm{CaY}>$ LaY (Table 3). Despite the slower kinetics observed, KY showed the highest adsorption capacity in comparison to the other Y zeolites. This was possibly

Table 2 Elemental analysis of all the $\mathrm{Y}$ zeolites

\begin{tabular}{|c|c|c|c|c|c|c|c|c|}
\hline Adsorbent & $\mathrm{SiO}_{2} / \mathrm{Al}_{2} \mathrm{O}_{3}$ & $\mathrm{Li}^{a}$ & $\mathrm{Na}^{a}$ & $\mathrm{~K}^{a}$ & $\mathrm{Ca}^{a}$ & $\mathrm{La}^{a}$ & $\begin{array}{l}\text { Summation of charge } \\
\text { on alkaline cations }{ }^{a}\end{array}$ & $\begin{array}{l}\text { Degree of ion } \\
\text { exchange, } \%\end{array}$ \\
\hline LiY (LiNaY) & 5.2 & 0.16 & 0.18 & $-^{b}$ & $-^{b}$ & $-^{b}$ & 0.34 & 47 \\
\hline $\mathrm{NaY}^{c}$ & 5.2 & $-^{b}$ & 0.32 & $-^{b}$ & $-^{b}$ & $-^{b}$ & 0.32 & 0 \\
\hline KY (KNaY) & 5.2 & $-^{b}$ & 0.02 & 0.30 & $-^{b}$ & $-^{b}$ & 0.32 & 94 \\
\hline $\mathrm{CaY}(\mathrm{CaNaY})$ & 5.2 & $-^{b}$ & 0.07 & ${ }^{b}$ & 0.13 & $-^{b}$ & 0.33 & 79 \\
\hline (LaNaY) & 4.98 & $-^{b}$ & 0.05 & & & 0.03 & 0.14 & 64 \\
\hline
\end{tabular}

${ }^{a}$ mol/100 gram zeolite. ${ }^{b}$ Under detection limit. ${ }^{c}$ Commercial NaY sample. 

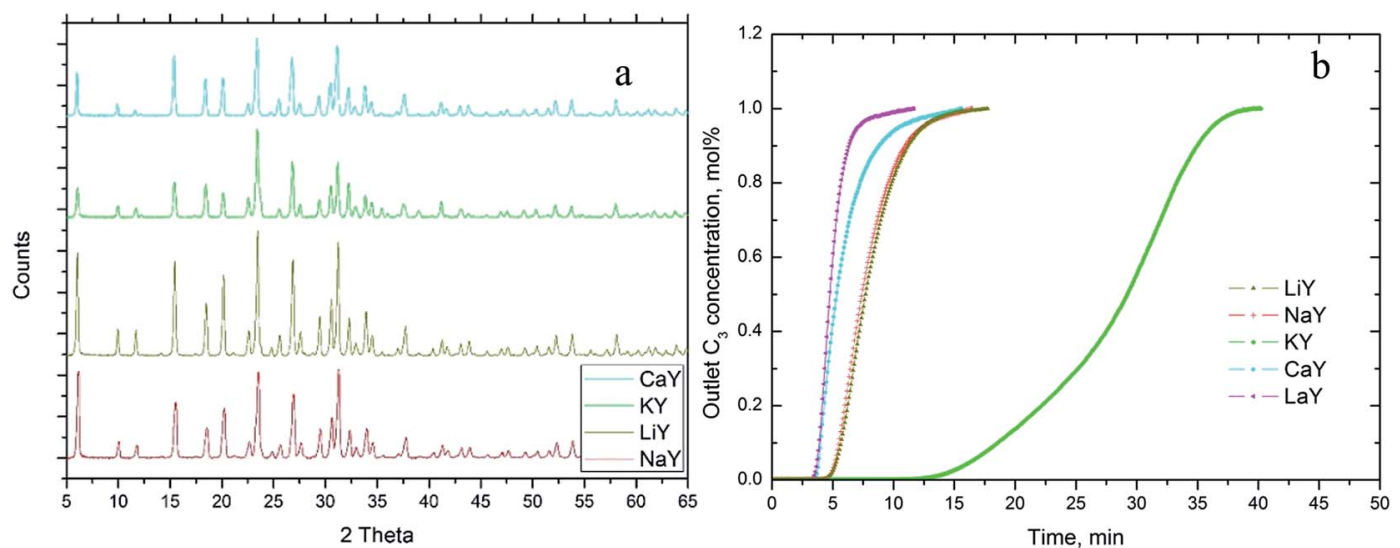

Fig. 2 (a) XRD results for $Y$ zeolites; (b) propane breakthrough results for $Y$ zeolites.

Table 3 Physical properties and $\mathrm{C}_{3} \mathrm{H}_{8}$ adsorption capacity on different $\mathrm{Y}$ zeolites

\begin{tabular}{|c|c|c|c|c|c|c|}
\hline Adsorbent & $\begin{array}{l}\text { Breakthrough } \\
\text { time }^{a}, \text { min }\end{array}$ & $\begin{array}{l}\text { Cation } \\
\text { size } \AA\end{array}$ & $\begin{array}{l}\text { Langmuir surface } \\
\text { area } \mathrm{m}^{2} \mathrm{~g}^{-1}\end{array}$ & $\begin{array}{l}\text { Polarizability } \\
\text { of cation, } 10^{-24} \mathrm{~cm}^{3}\end{array}$ & $\begin{array}{l}\text { Total numbers } \\
\text { of cations } / \mathrm{g}\left(10^{21}\right)\end{array}$ & $\begin{array}{l}\mathrm{C}_{3} \text { adsorption } \\
\text { capacity wt } \%\end{array}$ \\
\hline $\operatorname{LaY}\left(\mathrm{La}^{3+}\right)$ & 5.7 & 1.03 & 866 & - & 0.48 & 1.05 \\
\hline $\mathrm{NaY}\left(\mathrm{Na}^{+}\right)$ & 9.6 & 0.97 & 949 & 0.18 & 1.93 & 2.55 \\
\hline $\operatorname{LiY}\left(\mathrm{Li}^{+}\right)$ & 10.0 & 0.68 & 1043 & 0.029 & 2.05 & 2.92 \\
\hline $\mathrm{KY}\left(\mathrm{K}^{+}\right)$ & 33.3 & 1.33 & 858 & 0.84 & 1.93 & 8.69 \\
\hline
\end{tabular}

${ }^{a}$ Outlet concentration is $80 \%$ of the inlet concentration.

a function of the induced dipole moment and the relatively high polarizability of the $\mathrm{K}$ cations.

3.1.2 A zeolites. A zeolites are well known molecular sieves for air separation and have smaller pore sizes than FAU zeolites. In our current work, 3A (KA), 4A (NaA), and 5A (CaA) were chosen. The Langmuir surface area extracted from nitrogen adsorption isotherms of the A zeolites followed the trend $3 \mathrm{~A} \approx$ $4 \mathrm{~A}(\sim 0)<<5 \mathrm{~A}\left(520 \mathrm{~m}^{2} \mathrm{~g}^{-1}\right)$ (Fig. 3a and Table 4). We believe the low nitrogen adsorption in $3 \mathrm{~A}$ and $4 \mathrm{~A}$ was the result of the framework thermal shrinkage at liquid nitrogen temperature as that we observed previously. ${ }^{13}$ The mechanism was thoroughly studied by a collaboration work with Prof. Webley's group and published in $2012 .^{27}$

Fig. 3b shows the propane breakthrough curves obtained for the three different A zeolites. Interestingly, with $3 \mathrm{~A}$ and $4 \mathrm{~A}$, there was almost an immediate propane breakthrough while with $5 \mathrm{~A}$, breakthrough started 25 minutes after commencement of adsorption, suggesting good propane adsorption. Considering the size of propane is around $4.9 \AA$ which is bigger than the effective window size in $3 \mathrm{~A}$ and $4 \mathrm{~A}$, the immediate propane breakthrough curves of the two A zeolites suggested propane was unable to access the pores of the $3 \mathrm{~A}$ and $4 \mathrm{~A}$ materials. However, for $5 \mathrm{~A}$ zeolite, the divalent calcium cations are situated at the window sites and give apertures of $\sim 5 \AA$ which excludes molecules with diameter larger than $5 \AA$ thus allows access to the propane molecule. The calculated propane adsorption capacity on different A zeolites is shown in Table 4 . The results showed that $3 \mathrm{~A}, 4 \mathrm{~A}$ had little propane adsorption while $5 \mathrm{~A}$ had a very good propane adsorption capacity of 8.1 wt $\%$.

3.1.3 Carbon adsorbents. Carbon adsorbents were chosen because of their high surface area, micropore volume and hydrophobicity which favored hydrocarbon adsorption. There were 5 types of activated carbon selected for propane adsorption in our work. Carbon \#1 (96831) is derived from lignite. Carbon \#2 (10198) is derived from wood and steam activated. Carbon \#3 (Norit RB) is a steam activated carbon. Carbon \#4 (22874) is derived from peat and steam activated. Carbon \#5 (37771) is derived from coal and is steam activated.

The nitrogen adsorption isotherms for all the carbons are shown in Fig. 4a. All carbons exhibit type I isotherms. Some of the isotherms had small or no hysteresis loop, suggesting the microporous nature of the carbon (carbon \#2 and \#3). The others have hysteresis loops, revealing a more heterogeneous pore system (carbon \#1, \#4 and \#5). Surface area and pore volume information for all carbon samples are summarized in Table 5 .

Propane breakthrough experimental results for all the carbon adsorbents are presented in Fig. 4b. The breakthrough curve fronts for all the carbons were very steep, suggesting fast adsorption kinetics and a good effective bed usage. All the carbons had very similar breakthrough curve slopes, with the exception of carbon $\# 5$, which had a less steep front. This suggests the propane adsorption behavior in most of the carbons was similar. Propane adsorption capacities on all the carbons were calculated and are presented in Table 5, following 



Fig. 3 (a) Nitrogen adsorption isotherms; (b) $\mathrm{C}_{3} \mathrm{H}_{8}$ breakthrough result for A zeolites.

Table $4 \quad \mathrm{C}_{3} \mathrm{H}_{8}$ adsorption capacity on different $\mathrm{A}$ zeolites

\begin{tabular}{|c|c|c|c|c|}
\hline Adsorbent & $\mathrm{SiO}_{2} / \mathrm{Al}_{2} \mathrm{O}_{3}$ & $\begin{array}{l}\text { Cation } \\
\text { size } \AA\end{array}$ & $\begin{array}{l}\text { Langmuir surface } \\
\text { area } \mathrm{m}^{2} \mathrm{~g}^{-1}\end{array}$ & $\begin{array}{l}\mathrm{C}_{3} \mathrm{H}_{8} \text { adsorption } \\
\text { capacity wt } \%\end{array}$ \\
\hline $3 \mathrm{~A}(\mathrm{KA})$ & 1.95 & 1.33 & $-^{a}$ & 0.51 \\
\hline $5 \mathrm{~A}(\mathrm{CaA})$ & 1.99 & 0.99 & 520 & 8.10 \\
\hline
\end{tabular}

${ }^{a}$ Non-measurable when nitrogen gas molecules are used as adsorptive.

the trend from highest to lowest capacity as follows: carbon \#5 > $\# 4>\# 3>\# 2>\# 1$.

On careful examination of the physical properties of the carbons (Table 5), it was found the propane adsorption capacity is more dependent on the micropore volume $\left(V_{\text {micro }}\right)$ and surface area than the total pore volume $\left(V_{\text {total }}\right)$. Micropores are classified as those with pore diameters $<2 \mathrm{~nm}$.

3.1.4 Other structured adsorbents: SBA-15, beta-zeolite and Cu-BTC. The silica/alumina ratio in the beta-zeolite is 300 and the non-framework cation is hydrogen. The low alumina content of this zeolite means that, compared to the $\mathrm{A}$ and $\mathrm{X}$ zeolites used in this work, there is little charge on the betazeolite framework. SBA-15 is a structured silica material and has no charge on the pore network (that is, requires no charge compensating ions). Since the framework charge is low for both of these materials, the major difference in these two siliceous materials is the pore geometry. Information on the pore geometry of the beta-zeolite, SBA-15 and Cu-BTC can be seen in Fig. 5 and Table 6.

The nitrogen adsorption isotherm for beta-zeolite is a typical type I isotherm, with a narrow hysteresis loop, confirming the structure was microporous with a small amount of mesopores (Fig. 5a). The surface area of beta-zeolite is $866 \mathrm{~m}^{2}$ $\mathrm{g}^{-1}$ and micropore volume is $0.2 \mathrm{~cm}^{3} \mathrm{~g}^{-1}$ (Table 6). The synthesized SBA-15 has a surface area of $560 \mathrm{~m}^{2} \mathrm{~g}^{-1}$ (Table 6). It is worth noting that the micropore volume of SBA-15 is as low as $0.01 \mathrm{~cm}^{3} \mathrm{~g}^{-1}$, by far the lowest of the three materials in this series. However, SBA-15 contains a significant number of mesopores with pore size around $10 \mathrm{~nm}$ (mesopore volume $=$ $1.18 \mathrm{~cm}^{3} \mathrm{~g}^{-1}$ - Table 6).
The breakthrough results for these two materials show that 3.13 wt $\%$ propane adsorbed on beta-zeolite whereas SBA-15 propane sorption capacity was calculated to be only $0.51 \%$ (Fig. 5b and Table 6).

Given the main difference between SBA-15 and beta zeolite is the micropore volume, we concluded that propane adsorption occurred mainly in the micropores in these siliceous materials and that little or no propane was adsorbed in the mesopores.

$\mathrm{Cu}-\mathrm{BTC}$ is one of the best characterised MOF structures. The coordinated organic (BTC) ligands form small cavities of size 4.6 A that is close in size to that of the propane gas molecule $(3.8 \AA)$. Also the framework is relatively hydrophobic meaning water does not compete with propane for adsorption sites and the framework is stable under moisture-containing environments. The Cu-BTC synthesized in our work was highly microporous as can be seen from its nitrogen adsorption isotherm (Fig. 5a) and had a much higher surface area $\left(1770 \mathrm{~m}^{2} \mathrm{~g}^{-1}\right)$ than those of beta-zeolite and SBA-15 (Table 6). Propane exhibited good adsorption on Cu-BTC. Its propane adsorption capacity was calculated to be $4.79 \mathrm{wt} \%$, which was much higher than those on beta-zeolite and SBA-15. Similar to beta-zeolite and SBA-15, Cu-BTC has little network charge and therefore very weak electric fields with which to induce significant induced adsorption interaction. The dominant adsorbent/propane interaction in Cu-BTC would reduce to steric interactions in which pore size plays the most significant role. Analysis of the nitrogen adsorption isotherm shows Cu-BTC has a much smaller pore size and much larger micropore volume of $0.5 \mathrm{~m}^{3}$ $\mathrm{g}^{-1}$ (Table 5), than either beta-zeolite or SBA-15. The higher propane adsorption capacity of $\mathrm{Cu}$-BTC can therefore be 



Fig. 4 (a) Nitrogen adsorption isotherms; (b) $\mathrm{C}_{3} \mathrm{H}_{8}$ breakthrough results for carbon samples; (c) cartoon image for gas adsorbed in activated carbon.

Table $5 \quad \mathrm{C}_{3} \mathrm{H}_{8}$ adsorption capacity on different carbon samples ${ }^{a}$

\begin{tabular}{|c|c|c|c|c|}
\hline Carbon \#1 & 647 & 0.28 & 0.49 & 5.0 \\
\hline Carbon \#3 & 916 & 0.41 & 0.50 & 5.90 \\
\hline Carbon \#4 & 951 & 0.43 & 0.53 & 6.7 \\
\hline Carbon \#5 & 1054 & 0.50 & 0.68 & 8.58 \\
\hline
\end{tabular}

${ }^{a}$ Carbon \#1: 96831 carbon \#2: 22874 carbon \#3: 660689 carbon \#4:SL carbon \#5: 37771.

ascribed to the larger micropore volume of this material. Interestingly, although the surface area of Cu-BTC is almost double and the micropore volume is more than double that of beta-zeolite, the propane adsorption capacity is only $53 \%$ higher. This could indicate other factors aside from micropore volume and surface area contribute to the adsorption capacity in these materials.

In summary, pore size and the charge on the framework play the most significant roles in propane adsorption. For adsorbents that have no framework charge, the adsorbate and adsorbent interaction reduces to intrinsic interaction where pore size plays the critical role in binding energy. Micropores are more effective in adsorbing propane than the larger mesopores. Charged frameworks can generate electric fields which can enhance interaction between adsorbent and adsorbate.

\subsection{Ethane adsorption}

In Section 3.1 we examined propane adsorption on several different adsorbents. With the results obtained, we were able to identify the best material for propane adsorption (in terms of adsorption capacity) for each of the adsorbent groups. Since ethane and propane are the two components that are both similar in nature and the most difficult to separate during natural gas processing/purification, it was decided to test the selected adsorbents for ethane adsorption. Although the A zeolites, particularly $3 \mathrm{~A}$ and $4 \mathrm{~A}$ showed poor propane adsorption, it might have potential for ethane adsorption and therefore were chosen for testing as well.

Surface area and pore size information for all the tested adsorbents in this section can be found in the previous Section 

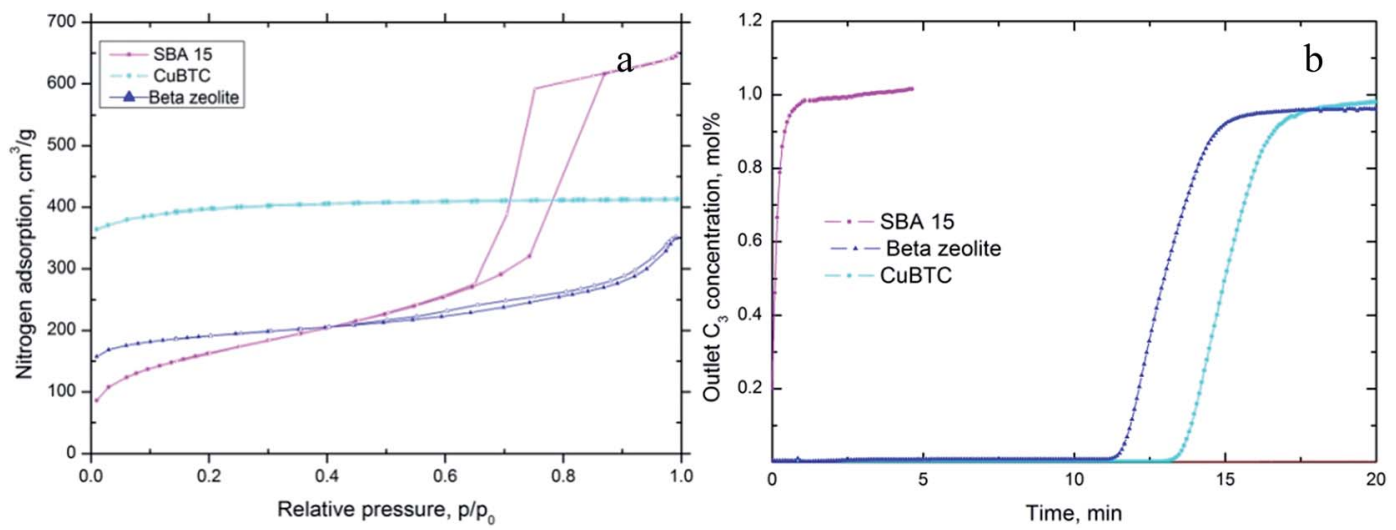

Fig. 5 (a) Nitrogen adsorption isotherms for SBA-15, Cu-BTC and BEA-zeolite; (b) $\mathrm{C}_{3} \mathrm{H}_{8}$ breakthrough results for SBA-15, beta-zeolite and CuBTC.

Table $6 \mathrm{C}_{3} \mathrm{H}_{8}$ adsorption capacity on SBA 15, BEA-zeolite and Cu-BTC

\begin{tabular}{lllll}
\hline Adsorbent & $\begin{array}{l}\text { BET surface } \\
\text { area }\left(\mathrm{m}^{2} \mathrm{~g}^{-1}\right)\end{array}$ & $\begin{array}{l}\text { Micropore volume, } V_{\text {micro }} \\
\left(\mathrm{cm}^{3} \mathrm{~g}^{-1}\right)\end{array}$ & $\begin{array}{l}\text { Mesopore volume, } V_{\text {meso }} \\
\left(\mathrm{cm}^{3} \mathrm{~g}^{-1}\right)\end{array}$ & $\begin{array}{l}\mathrm{C}_{3} \mathrm{H}_{8} \text { adsorption } \\
\text { capacity }(\mathrm{wt} \%)\end{array}$ \\
\hline SBA-15 & & 0.01 & 1.18 & 0.51 \\
BEA-zeolite & 560 & 0.2 & 0.31 & 3.13 \\
Cu-BTC & 866 & 0.51 & 0.13 & 4.79
\end{tabular}

3.1. Ethane breakthrough experimental results for all the selected adsorbents are presented in Fig. 6 and their ethane adsorption capacity is given in Table 7 .

Among the A zeolites, 3A showed immediate ethane breakthrough, suggesting no ethane adsorption on 3A. For 4A zeolite, the adsorption capacity was calculated to be $1.12 \mathrm{wt} \%$. The

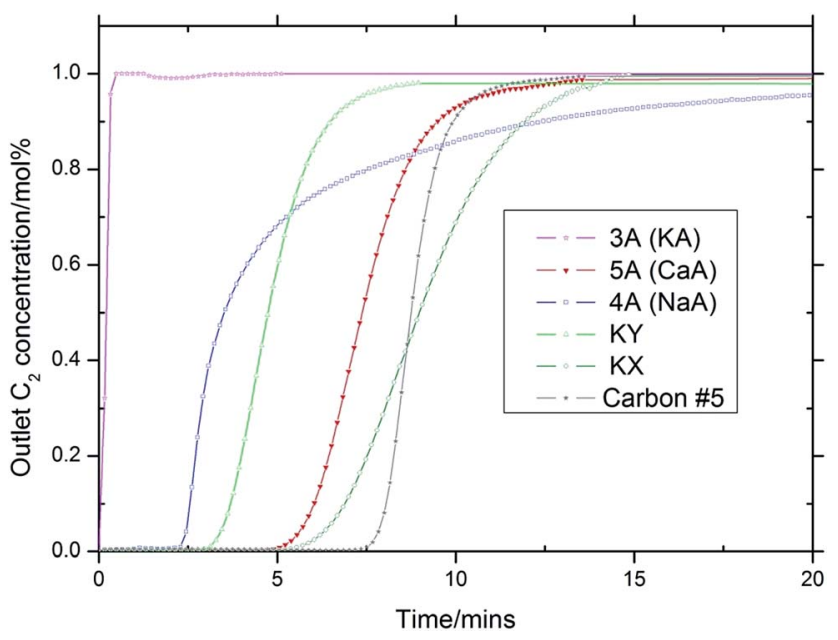

Fig. $6 \mathrm{C}_{2} \mathrm{H}_{6}$ breakthrough results for $A$ zeolites, $\mathrm{KY}, \mathrm{KX}$ and carbon \#5. breakthrough front of this zeolite was much more gradual than other A zeolites, suggesting a slower ethane adsorption rate, possibly due to slower diffusion into the pores of $4 \mathrm{~A}$ compared to the larger pore $5 \mathrm{~A}$ zeolite. Also, the divalent charge compensating ion in $5 \mathrm{~A}, \mathrm{Ca}^{2+}$ replaced two $\mathrm{Na}^{+}$ions so the total number of cations in $5 \mathrm{~A}$ was much less than that in $4 \mathrm{~A}$. This would open up more of the framework window access to ethane gas molecules, leading to more ethane adsorption in 5A (2.78 $\mathrm{wt} \%$ ) than in $3 \mathrm{~A}$ (none detected) and $4 \mathrm{~A}$ (1.12 wt\%).

KY zeolite showed a reasonable ethane adsorption (2.52 $\mathrm{wt} \%$ ) which was slightly less than that of $5 \mathrm{~A}(2.78 \mathrm{wt} \%)$ though KY had much higher surface area than 5A (Tables 3 and 4). The $\mathrm{SiO}_{2} / \mathrm{Al}_{2} \mathrm{O}_{3}$ ratio of $\mathrm{KY}$ is 5.2 (Table 2) while that of $5 \mathrm{~A}$ is 1.99 (Table 4), suggesting there was more charge on the $5 \mathrm{~A}$ framework than that of KY and consequently a stronger electric field generated in 5A. It would appear that framework charge has a greater effect on ethane adsorption capacity in this case than surface area. This is consistent with earlier work. ${ }^{18}$

The adsorption capacity of ethane on $\mathrm{KX}$ is $3.70 \mathrm{wt} \%$. Both $\mathrm{KY}$ and $\mathrm{KX}$ are FAU type zeolites. The pore size is very similar but the alumina content of the $\mathrm{X}$ zeolite is higher, meaning there is more charge on the $\mathrm{KX}$ framework. Given the only difference between $\mathrm{KX}$ and $\mathrm{KY}$ is the number of charge compensating ions (higher in $\mathrm{X}$ ) it is reasonable to conclude that the difference in ethane adsorption capacity between the

Table $7 \quad \mathrm{C}_{2} \mathrm{H}_{6}$ adsorption capacity on different $\mathrm{A}$ zeolites

\begin{tabular}{llllll}
\hline Adsorbent & $3 \mathrm{~A}(\mathrm{KA})$ & $4 \mathrm{~A}(\mathrm{NaA})$ & $5 \mathrm{~A}(\mathrm{CaA})$ & $\mathrm{KY}$ & $\mathrm{KX}$ \\
$\mathrm{C}_{2} \mathrm{H}_{6}$ adsorption capacity wt\% & 0.08 & 1.12 & 2.78 & 2.52 & 3.70
\end{tabular}


two can be attributed to the framework charge compensating ions. With the result obtained here we can conclude that ethane adsorption is a function of charge on the zeolite framework.

As was the case in the propane adsorption experiments, carbon \#5 showed the best adsorption capacity for ethane for all the sorbents tested. This was attributed to its larger surface area and micropore volume compared to the other materials.
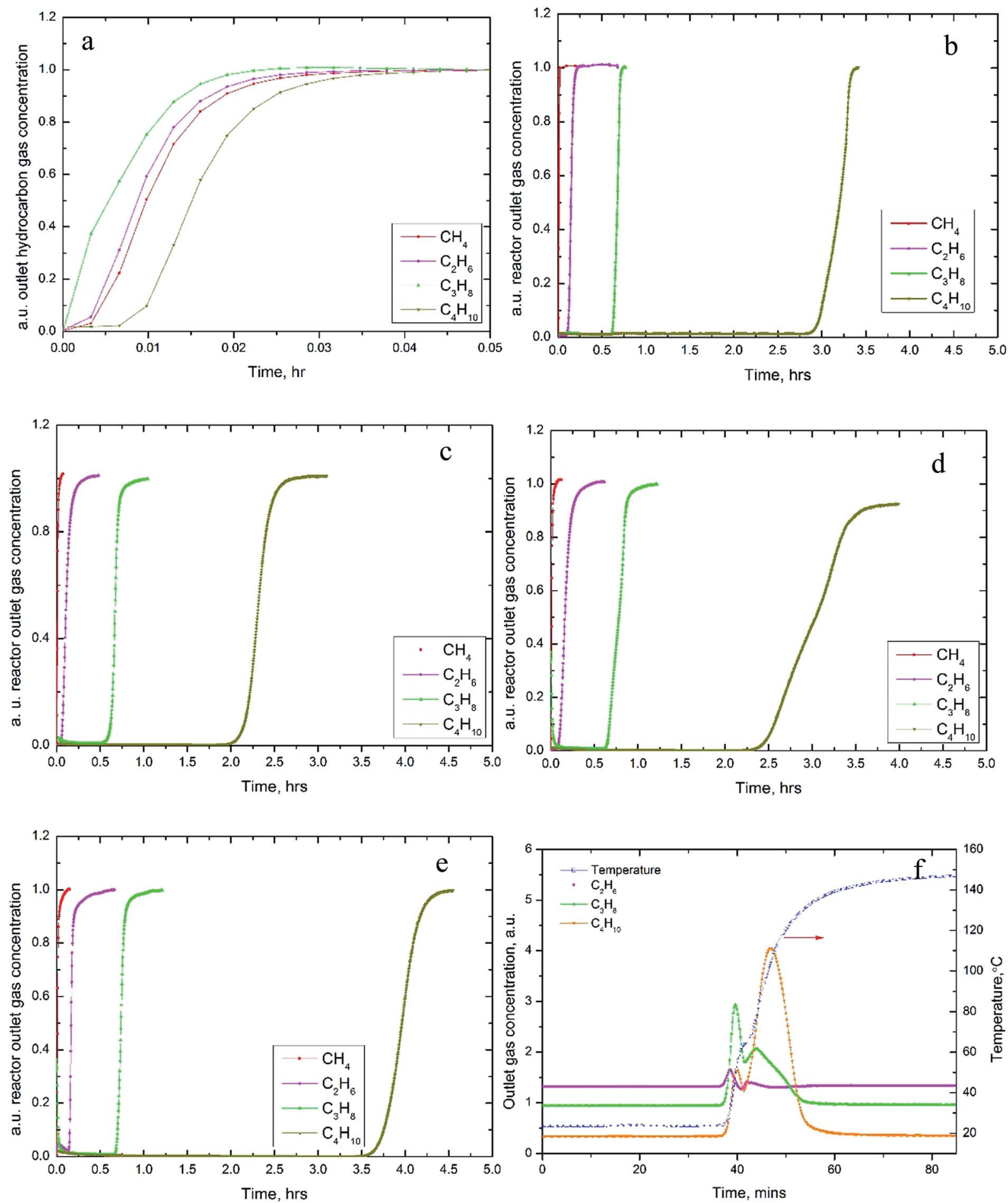

Fig. 7 Breakthrough results (a) 3A (b) 5A (c) KY (d) KX (e) carbon \#5 (f) desorption vs. Temperature (KY). Note: arbitrary unit 1.0 corresponds to the saturation gas concentration of the individual gas $(0.504 \mathrm{~mol} \% \mathrm{n}$-butane, $2.51 \mathrm{~mol} \%$ propane, $4.98 \mathrm{~mol} \%$ ethane).

\subsection{Natural gas separation}

3.3.1 Natural gas adsorption and separation on selected adsorbents. In this section a comparison of adsorption behavior of natural gas on the five selected good adsorbents as determined by adsorption capacities was presented, Fig. 7a-e.

In general, butane, propane were retained longer than ethane on the five selected adsorbents. 3A showed little 
adsorption of ethane and propane and small amount of butane. $\mathrm{KY}, \mathrm{KX}$ and 5A all showed good adsorption for all hydrocarbons, with methane breakthrough firstly, ethane second, then propane and last with butane, suggesting an excellent separation between them. But under the current experimental conditions, 5A performed better in terms of separation. It took 3 hours for the $0.504 \mathrm{~mol} \% \mathrm{n}$-butane to completely breakthrough from the 5A column. Carbon \#5 showed better adsorption behavior than all the zeolite adsorbents, with propane and especially butane breaking through from the column in 3.5 hours.

3.3.2 Desorption. KX was selected to investigate the desorption properties of the hydrocarbons. After the adsorption column was saturated with hydrocarbons (when butane broke through the column), simulated natural gas feed was terminated and inert gas (Ar) was purged through the reactor while the reactor was heated to $150{ }^{\circ} \mathrm{C}$. We have observed that lighter hydrocarbons desorbed earlier than the heavier ones (Fig. 7f). Ethane desorbed at temperatures as low as $30{ }^{\circ} \mathrm{C}$ while propane desorbed around $50{ }^{\circ} \mathrm{C}$. Butane started desorbing at $40{ }^{\circ} \mathrm{C}$ but the majority was desorbed at around $100{ }^{\circ} \mathrm{C}$. This result suggested hydrocarbons having higher carbon numbers generally have higher binding energy with the zeolite adsorbents, and therefore require higher temperatures to remove them.

3.3.3 Adsorption cycle experiment. The cyclability of the adsorbents was investigated in this section. In general, after the adsorbent column was saturated with hydrocarbons (after butane broke through the column), desorption was conducted as described in 3.3.2. After desorption at elevated temperature $\left(150{ }^{\circ} \mathrm{C}\right)$, the reactor was cooled to room temperature in inert gas and adsorption started again once the outlet gas signal stabilised. 4 cycles of adsorption and desorption were run in the current experiment. The results were shown in Fig. 8. It is clear from the results that methane, ethane, propane and butane separated from each other very well during the 4 cycles tested in our work, suggesting the experimental regeneration condition $\left(150{ }^{\circ} \mathrm{C}\right)$ was sufficient to remove the adsorbed hydrocarbons; and that the adsorbent material has shown very good cyclability.

\subsection{Conclusions}

Usually, refrigeration cycles but not solid adsorbents are used for natural gas purification. Our work has thoroughly proved that solid adsorbent materials can be used to adsorb and separate heavier hydrocarbons from natural gas. We have successfully demonstrated ethane, propane and butane adsorption and separation from methane on a range of adsorbents. Factors critical in the selection of suitable adsorbents for adsorption and separation of hydrocarbon components in natural gas include: framework charge; surface area and micropore volume; and adsorption kinetics. For adsorbents that have no framework charge, the adsorbate and adsorbent
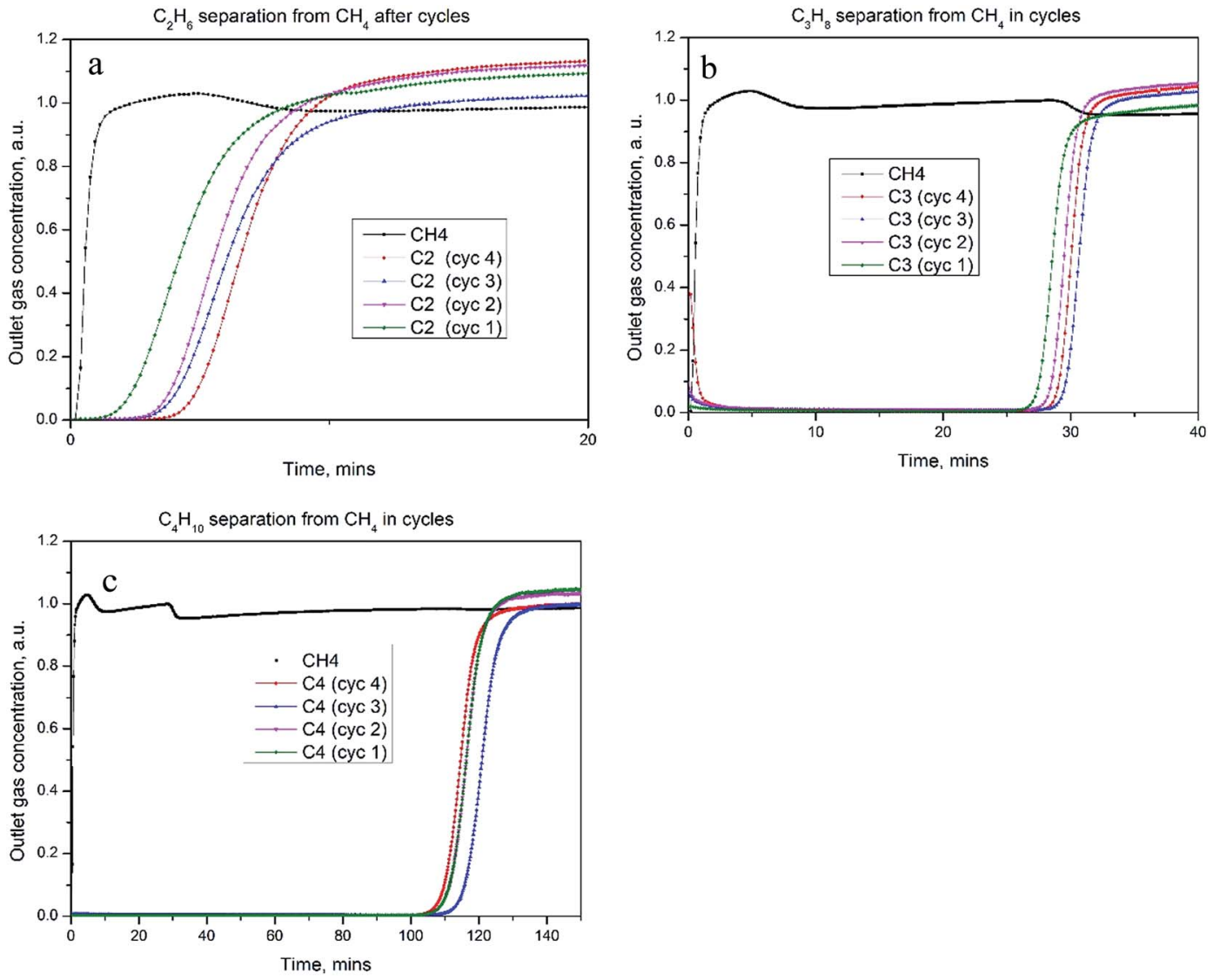

Fig. 8 Behavior of $\mathrm{C}_{2} \mathrm{H}_{6}$ (C2) (a), $\mathrm{C}_{3} \mathrm{H}_{8}(\mathrm{C} 3)(\mathrm{b})$ and $\mathrm{C}_{4} \mathrm{H}_{10}$ (C4) (c) during adsorption cycles. 
interaction reduces to intrinsic interaction where pore size plays the critical role in binding energy. Micropores are more effective in adsorbing propane than the larger mesopores. It is postulated that charged frameworks can generate electric fields which can enhance interaction between adsorbent and adsorbate.

Study of adsorbate gas mixtures that simulated the natural gas compositions prior to liquefaction further confirmed the hydrocarbon separation properties on the selected good adsorbents. The cycling behavior of adsorbent materials was proven to be excellent and little deterioration was observed after cycles.

Although solid adsorbents aren't typically used for natural gas purification, those studied in this work have shown promise for separation of compounds similar in chemical makeup. While solid adsorbents might have limited appeal in large-scale LNG and gas processing operations, there looks to be some substantial opportunity for application of these materials in small-scale and distributed operations.

\section{Acknowledgements}

The authors would like to acknowledge Chevron Corp. who, through the Western Australian Energy Research Alliance (WAERA), has supported this work. The authors are also grateful to CSIRO for providing additional financial support.

\section{References}

1 H. Yang, Z. Xu, M. Fan, R. Gupta, R. B. Slimane, A. E. Bland and I. Wright, J. Environ. Sci., 2008, 20, 14-27.

2 C. A. Grande, J. Gascon, F. Kapteijn and A. E. Rodrigues, Chem. Eng. J., 2010, 160, 207-214.

3 R. J. Grant and M. Manes, Ind. Eng. Chem. Fundam., 1966, 5, 490-498.

4 R. Harlfinger, D. Hoppach, U. Quaschik and K. Quitzsch, Zeolites, 1983, 3, 123-128.

5 T.-L. Hu, H. Wang, B. Li, R. Krishna, H. Wu, W. Zhou, Y. Zhao, Y. Han, X. Wang, W. Zhu, Z. Yao, S. Xiang and B. Chen, Nat. Commun., 2015, 6, 1-9.

6 Y. J. Wu, Y. Yang, X. M. Kong, P. Li, J. G. Yu, A. M. Ribeiro and A. E. Rodrigues, J. Chem. Eng. Data, 2015, 60, 2684-2693.

7 J. Kim, L.-C. Lin, R. L. Martin, J. A. Swisher, M. Haranczyk and B. Smit, Langmuir, 2012, 28, 11923-11928.

8 N. Lamia, M. A. Granato, P. S. A. Gomes, C. A. Grande, L. Wolff, P. Leflaive, D. Leinekugel-le-Cocq and A. E. Rodrigues, Sep. Sci. Technol., 2009, 44, 1485-1509.
9 N. Lamia, M. Jorge, M. A. Granato, F. A. Almeida Paz, H. Chevreau and A. E. Rodrigues, Chem. Eng. Sci., 2009, 64, 3246-3259.

10 W. K. Lewis, E. R. Gilliland, B. Chertow and D. Bareis, J. Am. Chem. Soc., 1950, 72, 1160-1163.

11 S. E. Siporin, B. C. McClaine and R. J. Davis, Langmuir, 2003, 19, 4707-4713.

12 T. H. Yeon, H. S. Han, E. D. Park and J. E. Yie, Microporous Mesoporous Mater., 2009, 119, 349-355.

13 F. N. Ridha, Y. X. Yang and P. A. Webley, Microporous Mesoporous Mater., 2009, 117, 497-507.

14 M. Palomino, A. Corma, F. Rey and S. Valencia, Langmuir, 2009, 26, 1910-1917.

15 H. Liu, Z. Zhang, B. H. Chen and Y. Zhao, J. Porous Mater., 2008, 15, 119-125.

16 O. Talu, S. Y. Zhang and D. T. Hayhurst, J. Phys. Chem., 1993, 97, 12894-12898.

17 O. M. Dzhigit, A. V. Kiselev, T. A. Rachmanova and S. P. Zhdanov, J. Chem. Soc., Faraday Trans. 1, 1979, 75, 2662-2677.

18 Y. Yang, N. Burke, J. Zhang, S. Huang, S. Lim and Y. Zhu, RSC $A d v .$, 2014, 4, 7279-7287.

19 H. Vinh-Thang, Q. L. Huang, M. Eic, D. Trong-on and S. Kaliaguine, Langmuir, 2005, 21, 5094-5101.

20 K. Kosuge, S. Kubo, N. Kikukawa and M. Takemori, Langmuir, 2007, 23, 3095-3102.

21 H. M. Wen, B. Li, H. L. Wang, R. Krishna and B. L. Chen, Chem. Commun., 2016, 52, 1166-1169.

22 G. G. Chang, B. Li, H. L. Wang, T. L. Hu, Z. B. Bao and B. L. Chen, Chem. Commun., 2016, 52, 3494-3496.

23 M. Eddaoudi, J. Kim, N. Rosi, D. Vodak, J. Wachter, M. O'keeffe and O. M. Yaghi, Science, 2002, 295, 469-472.

24 K. C. Szeto, K. P. Lillerud, M. Tilset, M. Bjorgen, C. Prestipino, A. Zecchina, C. Lamberti and S. Bordiga, J. Phys. Chem. B, 2006, 110, 21509-21520.

25 D. Y. Zhao, J. L. Feng, Q. S. Huo, N. Melosh, G. H. Fredrickson, B. F. Chmelka and G. D. Stucky, Science, 1998, 279, 548-552.

26 Y. K. Seo, G. Hundal, I. T. Jang, Y. K. Hwang, C. H. Jun and J. S. Chang, Microporous Mesoporous Mater., 2009, 119, 331337.

27 J. Shang, G. Li, R. Singh, Q. Gu, K. M. Nairn, T. J. Bastow, N. Medhekar, C. M. Doherty, A. J. Hill, J. Z. Liu and P. A. Webley, J. Am. Chem. Soc., 2012, 134, 19246-19253. 